\title{
Intracranial Anterior Circulation
}

National Cancer Institute

\section{Source}

National Cancer Institute. Intracranial Anterior Circulation. NCI Thesaurus. Code C32084.

A term referring to the brain area that is supplied by both the right and the left internal carotid arteries and their arterial branches. 